\title{
Congratulations to the 11 new academicians of the Chemistry Division, Chinese Academy of Sciences
}

\begin{abstract}
Miao Zhang*
Chemical Synthesis Editorial Office, Xi'an 710077, Shaanxi, China.

*Correspondence to: Miao Zhang, Chemical Synthesis Editorial Office, Suite 1504, Plaza A, Xi'an National Digital Publishing Base, No. 996 Tiangu 7th Road, Gaoxin District, Xi'an 710077, Shaanxi, China. E-mail: editorialoffice@chesynjournal.com

How to cite this article: Zhang M. Congratulations to the 11 new academicians of the Chemistry Division, Chinese Academy of Sciences. Chem Synth 2021;1:13. https://dx.doi.org/10.20517/cs.2021.18
\end{abstract}

Received: 18 Nov 2021 Accepted: 19 Nov 2021 Published: 19 Nov 2021

Academic Editor: Bao-Lian Su Copy Editor: Xi-Jun Chen Production Editor: Xi-Jun Chen

The Chinese Academy of Sciences (CAS) announced the election of 65 new academicians and 25 foreign members on November 18, 2021. Chemical Synthesis as an emerging leading new journal of chemical science, we are very pleased to highlight the outstanding achievements of the 11 new academicians of the CAS Chemistry Division to congratulate their election and their significant contribution to the development of chemical science. Their names are listed in Table 1.

Xian-He Bu (Figure 1, School of Materials Science and Engineering, Nankai University, China) focuses on the research of coordination polymer materials and has made pioneering and leading work in the function orientation, structure control, and precision synthesis of coordination polymers. He has been continuously selected into the Elsevier's List of Chinese Most Cited Researchers since 2016. He presided over the completion of "Coordination Polymer Construction and Structure Performance Control" and won the Second Prize of the State Natural Science Award of China in 2014.

Lifeng Chi (Figure 2, College of Nano Science \& Technology, Soochow University, China) focuses on the research of supramolecular chemistry on surfaces, including molecular assembly and on-surface reactions, molecular patterning and structured functional surfaces. She won the ACS Nano Lectureship Award in 2016, and the International Union of Pure and Applied Chemistry Distinguished Women in Chemistry or Chemical Engineering in 2017. She was elected as a Foreign Member of the European Academy of Sciences (Academia Europaea) and a Member of the Chinese Chemical Society in 2020. 
Table 1. List of the 11 new academicians of the CAS Chemistry Division

\begin{tabular}{|c|c|c|c|c|}
\hline No. & Name & Age & Major & Affiliation \\
\hline 1 & Xian-He Bu & 56 & Inorganic Chemistry & Nankai University \\
\hline 2 & Lifeng Chi & 63 & Physical Chemistry & Soochow University \\
\hline 3 & Yu Fang & 64 & Physical Chemistry & Shaanxi Normal University \\
\hline 4 & Maili Liu & 62 & Analytical Chemistry & $\begin{array}{l}\text { Innovation Academy for Precision Measurement Science and } \\
\text { Technology, CAS }\end{array}$ \\
\hline 5 & Guanghui Ma & 56 & Biochemical Engineering & Institute of Process Engineering, CAS \\
\hline 6 & Yuguang $\mathrm{Ma}$ & 57 & Polymer Chemistry and Physics & South China University of Technology \\
\hline 7 & Mei-Xiang Wang & 60 & Organic Chemistry & Tsinghua University \\
\hline 8 & Su-Yuan Xie & 53 & Inorganic Chemistry & Xiamen University \\
\hline 9 & Biao Yu & 53 & Organic Chemistry & Shanghai Institute of Organic Chemistry, CAS \\
\hline 10 & Ying-Jin Yuan & 57 & $\begin{array}{l}\text { Biochemical Engineering (Synthetic } \\
\text { Biology) }\end{array}$ & Tianjin University \\
\hline 11 & Xiang Zhou & 58 & Chemical Biology & Wuhan University \\
\hline
\end{tabular}

CAS: Chinese Academy of Sciences.

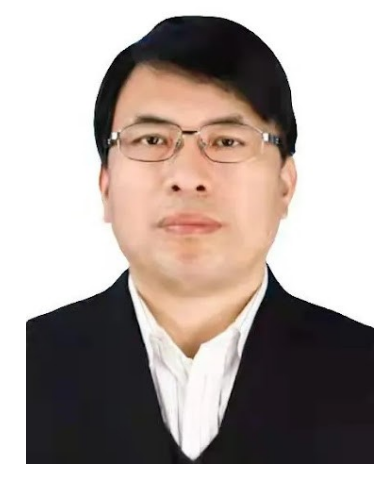

Figure 1. Academician Xian-He Bu (retrieved from: http://news.nankai.edu.cn/ywsd/system/2021/11/18/030048954.shtml).

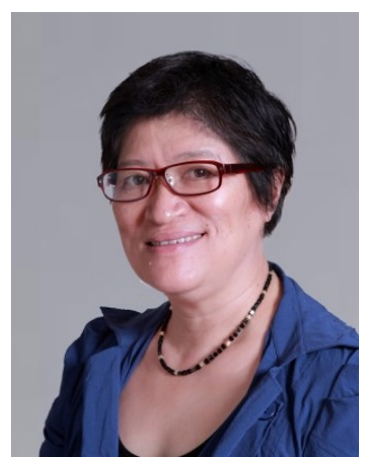

Figure 2. Academician Lifeng Chi (retrieved from: https://www.chemsoc.org.cn/member/senior/54582.html).

Yu Fang (Figure 3, School of Chemistry \& Chemical Engineering, Shaanxi Normal University, China) is engaged in thin film-based fluorescence sensing and molecular gel research. In scientific research, he insisted on the whole chain research from basic research to technological innovation, and then to industrial application, and made outstanding contributions. He won the Shaanxi Science and Technology Awards and Chemical Outstanding Contribution Award. 


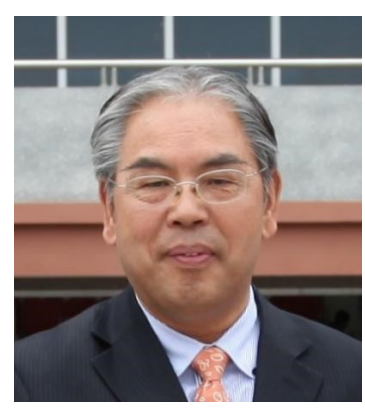

Figure 3. Academician Yu Fang (retrieved from: https://www.chemsoc.org.cn/member/fellow/135961.html).

Maili Liu (Figure 4, Innovation Academy for Precision Measurement Science and Technology, CAS, China) is committed to promoting the independent development and industrialization of nuclear magnetic resonance spectroscopy and imaging instruments, and enhancing the construction of biological nuclear magnetic resonance spectroscopy analysis disciplines, teams, and platforms, which has made important contributions to the development of China's spectral analysis disciplines.

Guanghui Ma (Figure 5, Institute of Process Engineering, CAS, China) focuses on the preparation of biological particles with uniform size and controllable structure, and their applications in biological separation and pharmaceutical engineering. She is the winner of the National Outstanding Youth Fund (2001). She also won the first prize of the Natural Science Award (2020) of the Chinese Society of Particles and the Hou Debang Chemical Technology Innovation Award of The Chinese Society of Chemical Industry and Engineering Society of China (2014).

Yuguang Ma (Figure 6, School of Materials Science and Engineering, South China University of Technology, China) is committed to the basic scientific research of organic/polymer optoelectronic materials, and his research results have made important contributions to the development of the second generation of phosphorescence and a new generation of inexpensive pure organic electroluminescent materials. He is the Professor of Cheung Kong Scholars Program, winner of the National Outstanding Youngster Science Fund. He won the Second Prize of the State Natural Science Award of China in 2009.

Mei-Xiang Wang (Figure 7, Department of Chemistry, Tsinghua University, China) focuses on the development of innovative macrocyclic and supramolecular chemistry. Using a multi-faceted approach, his group also studies non-covalent anion-p interactions as a fundamental motif and exploits them for a driving force to construct a diversity of supramolecular systems. In addition, they strive to develop chiral supramolecular system of inherently chiral macrocyclic compounds. He is the winner of the National Outstanding Youngster Science Fund (1997).

Su-Yuan Xie (Figure 8, College of Chemistry and Chemical Engineering, Xiamen University, China) devoted himself to the research of fullerenes and released the synthesis of a representative series of fullerenes (chlorides or hydrides). His overall achievements in the synthesis of new fullerenes with adjacent five-membered rings have reached the international advanced level. He is the Professor of Cheung Kong Scholars Program, winner of the National Outstanding Youngster Science Fund. He won the Second Prize of the State Natural Science Award of China twice. 


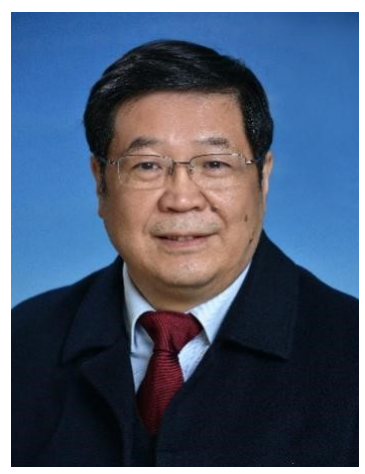

Figure 4. Academician Maili Liu (retrieved from: http://www.apm.cas.cn/sourcedb_apm_cas/zw/rck/zgj_rck/201912/t20191212_5452685.html).

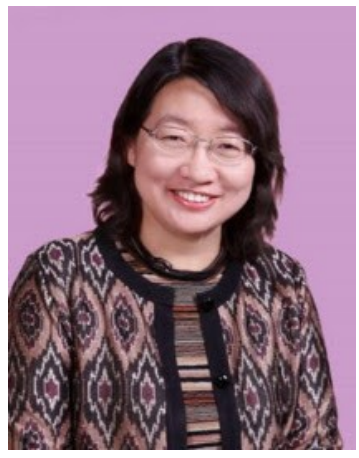

Figure 5. Academician Guanghui Ma (retrieved from: http://www.ipe.cas.cn/sourcedb_ipe_cas/zw/zjrc/yjy/202105/t20210511_6012366.html).

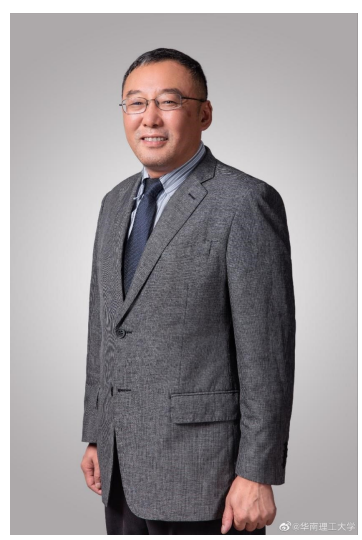

Figure 6. Academician Yuguang Ma (retrieved from: https://weibo.com/5549605449/L21xyoKPI).

Biao Yu (Figure 9, Shanghai Institute of Organic Chemistry, CAS, China) focuses on the total synthesis, synthetic methodology, and chemical biology research of complex oligosaccharides, glycoconjugates, and other natural products with important physiological activities. He is the first Chinese scientist to receive the Roy L. Whistler Award in Carbohydrate Chemistry, which is the highest international award in the field of sugar chemistry. He won the National Outstanding Youngster Science Fund (2000), and the Second Prize of the State Natural Science Award of China (2010). 


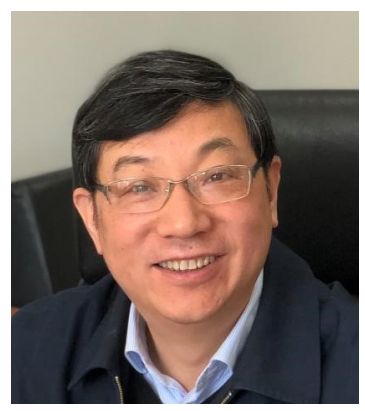

Figure 7. Academician Mei-Xiang Wang (retrieved from: https://www.chem.tsinghua.edu.cn/info/1097/2669.htm).

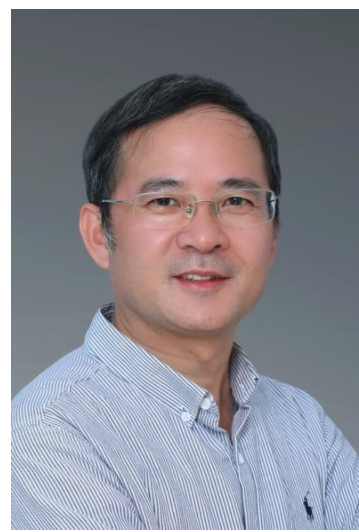

Figure 8. Academician Su-Yuan Xie (retrieved from: https://www.chemsoc.org.cn/member/fellow/39870.html).

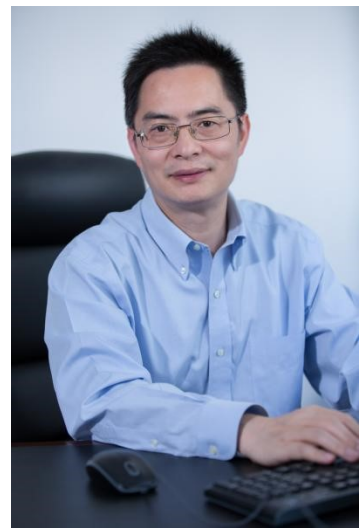

Figure 9. Academician Biao Yu (retrieved from: http://sourcedb.sioc.cas.cn/cn/expert/200906/t20090621_1750779.html).

Ying-Jin Yuan (Figure 10, School of Chemical Engineering and Technology, Tianjin University, China) has been working in the frontier and application fields of biochemical industry, including synthetic biology, systems biotechnology, biopharmaceutical, and bioenergy. Dr. Yuan is the recipient of numerous awards, including the leader of the National Creative Group Fund from the National Natural Science Foundation of China (NSFC), chief scientist of the National Basic Research Program, chief scientist of the major High Tech R\&D Program on Synthetic Biology. He is a recipient of the NSFC Outstanding Scholar Funds (2004). 


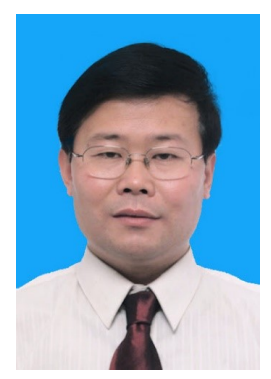

Figure 10. Academician Ying-Jin Yuan (retrieved from: http://www.tju.edu.cn/info/1035/1190.htm).

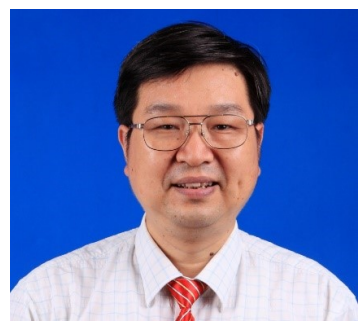

Figure 11. Academician Xiang Zhou (retrieved from: https://www.chemsoc.org.cn/member/senior/133949.html).

Xiang Zhou (Figure 11, College of Chemistry and Molecular Sciences, Wuhan University, China) is devoted to the research of nucleic acid chemical biology, and his main research directions are: small molecule recognition of nucleic acid structure and its function regulation, and the application of nucleic acid chemistry technology in disease diagnosis and treatment. The team led by Dr. Zhou has achieved internationally influential and innovative results and promoted the development of nucleic acid chemical biology research. He is the winner of the National Outstanding Youngster Science Fund (2004), and a Fellow of the Royal Society of Chemistry.

On behalf of the Chemical Synthesis Editorial Office and all members of the Editorial Board, we would like to express our warm congratulations to them!

\section{DECLARATIONS}

Authors' contributions

The author contributed solely to the article.

\section{Availability of data and materials}

Not applicable.

\section{Financial support and sponsorship}

None.

\section{Conflicts of interest}

The author declared that there are no conflicts of interest.

\section{Ethical approval and consent to participate}

Not applicable. 


\section{Consent for publication}

Not applicable.

\section{Copyright}

(c) The Author(s) 2021. 